\title{
AS AÇÕES REVISIONAIS DO FGTS: ASPECTOS, REQUISITOS E POTENCIAIS DECISÕES
}

\section{FGTS REVISIONAL LAWSUITS: ASPECTS, REQUIREMENTS AND POTENTIAL DECISIONS}

\author{
${ }^{1}$ Jerfferson Da Mata Almeida \\ ${ }^{2}$ Tatiana Bhering Serradas Bon De Sousa Roxo
}

\section{RESUMO}

O Fundo de Garantia por tempo de Serviço (FGTS) instituído em 1966, através da Lei 5.107 e atualmente ditado pela Lei 8.036/90, é um fundo dotado de cunho social custeando o sistema de habitação e infraestrutura como formas principais, bem como atendendo ao trabalhador em desamparo. A todo recolhimento mensal, custeado pelo empregador ao empregado celetista, esta conta vinculada e compulsória mantida na Caixa Econômica Federal sofre atualizações pela Taxa Referencial (TR) acrescida de juro médio anual de 3\%. Desde o ano de 1999 o saldo do FGTS vem sofrendo com baixas na TR, diminuída pelas premissas de seu cálculo face a redução gradativa da taxa Selic, não atingindo nem mesmo o montante inflacionário em alguns períodos, acarretando perdas aos trabalhadores, sendo origem e motivo de enorme volume de demandas no Judiciário com o objetivo de evitar esta corrosão a sua propriedade. Merece o tema explanação e explicação sob os fundamentos e argumentos levantados pelos trabalhadores, evidenciando seus aspectos com a apreciação de potenciais decisões acerca do tema que se apresenta na atualidade.

Palavras-chave: Fundo de garantia por tempo de serviço, Atualização monetária, Prescrição, Juros, Taxa referencial

\begin{abstract}
Enacted in 1966 by the Law 5.107 and currently dictated by the Law 8.036/90, the employee's dismissal fund (FGTS) works as a social nature fund to defray the housing and infrastructure system, and also to help the helplessness worker. Every monthly payment, compulsorily paid by the employer to every employee hired under employment laws (CLT), is deposited at CEF where the balance is updated by the Reference Rate (TR) plus an annual average interest rate of $3 \%$. Since 1999, due to the gradual reduction of the Selic - the interest rate from which the TR is extracted - the employee's FGTS balance is being partially eroded for this monetary adjustment does not offset the inflation rate at some periods. This has entailed a surging amount of lawsuits with the aim of reverting occasional losses by the CLT employees in their FGTS accounts. This paper discusses the subject in the light of the workers' pleas and arguments, with special emphasis on its aspects and potential decisions on the subject.
\end{abstract}

Keywords: Guarantee insurance, Monetary restatement rate, Injunction lapse lawsuit/prescribe, Interest, Reference rate (tr)

\footnotetext{
${ }^{1}$ Mestre em Direito pelo Faculdades Milton Campos, Minas Gerais (Brasil). Professor do Centro Universitário Newton Paiva, Minas Gerais (Brasil). E-mail: damataadv@gmail.com

${ }^{2}$ Mestre em Direito do Trabalho pela Pontifícia Universidade Católica de Minas Gerais - PUC/MG, Minas Gerais (Brasil). Professora do curso de Direito do Centro Universitário Newton Paiva, Minas Gerais (Brasil). E-mail: tatiroxo@gmail.com
} 


\section{INTRODUÇÃO}

O sistema do Fundo de Garantia por Tempo de Serviço foi instituído no ordenamento jurídico brasileiro no ano de 1966, inicialmente como um sistema paralelo ao sistema estabilitário celetista. No ano de 1988, com o advento da Constituição da República Federativa do Brasil, o FGTS foi generalizado a todos os trabalhadores brasileiros contratados pelo regime celetista.

Pretendemos, aqui, analisar a evolução da regulamentação desse instituto jurídico trabalhista desde a sua instituição até os dias de hoje, de maneira a entender a lógica e a finalidade principal dos depósitos do FGTS.

Feito isso, passaremos à análise da taxa de atualização utilizada para o Fundo de Garantia por Tempo de Serviço: a taxa referencial, com enfoque no estudo de julgados sobre o tema.

Ao fim, analisaremos quais são as possibilidades de propositura de ações revisionais para a discussão dos expurgos inflacionários do fundo em comento, com destaque para o prazo prescricional que deve ser aplicado a tais ações e às possíveis decisões que podem ser dadas, de maneira a atender os anseios dos trabalhadores.

\section{O FUNDO DE GARANTIA POR TEMPO DE SERVIÇO: REGULAMENTAÇÃO E ORIGEM}

A constante modificação das interações sociais exige que o direito esteja, também, em constante evolução, de forma a acompanhar os anseios da sociedade. Neste sentido, o Direito do Trabalho, especialmente no que concerne às interações trabalhador-tomador de serviços, evolui de forma a garantir os direitos sociais dos trabalhadores e, ao mesmo tempo, otimizar as relações econômicas e aumentar a produtividade e o emprego. Com o aumento da produtividade, além de maiores lucros para o empregador, os empregados são beneficiados com maiores garantias e, assim, aumento do seu patamar social.

O Fundo de Garantia por Tempo de Serviço, FGTS, é um direito social trabalhista que foi instituído no ordenamento jurídico no ano de 1966, com a edição da Lei 5.107. Inicialmente, como um sistema alternativo às indenizações por tempo de serviço e à garantia de emprego até então previstas na Consolidação das Leis Trabalhistas. Para compreender o regime do FGTS e a sua finalidade, mister analisar o antigo regime estabilitário adotado no 
Brasil. A CLT prevê, em seus artigos 492 e 494 (BRASIL), que o empregado estabilitário, ou seja, o empregado com um período de trabalho de mais de 10 anos na mesma empresa, somente poderia ser dispensado caso praticasse uma falta grave e, ainda assim, após ser submetido à ação judicial chamada “inquérito para apuração de falta grave". O resultado da ação é a autorização judicial para a rescisão do contrato de trabalho do empregado estável, chamado "estável decenal".

Aos empregados que não tivessem completado os 10 anos contínuos de serviços na empresa eram garantidas indenizações proporcionais ao tempo de serviço previstas na CLT: aos empregados com um ano ou mais de emprego era devida uma indenização correspondente ao valor do seu salário mensal, multiplicada pelo número de anos trabalhados.

Esse antigo regime estabilitário previsto na CLT mostrou-se deficiente em diversos aspectos. Segundo Edmo Lima de Marca (1972), o sistema não amparava aqueles que se aposentassem; fazia com o que o empregado se vinculasse àquele emprego, mesmo que tivesse melhores oportunidades, de forma a não perder o período ali já trabalhado; consequentemente, também desestimulava o aperfeiçoamento da mão de obra, uma vez que não havia interesse dos empregados em se especializar para trabalhar em outras empresas e, caso o empregado viesse a cometer a falta grave, perderia a indenização de todo o período trabalhado. Do ponto de vista das empresas, ao longo dos anos, o passivo trabalhista em caso de despedimento dos empregados era significativo, o que, por sua vez, desestimulava o mercado de trabalho.

Diante de todos esses fatores, buscou-se um sistema que aperfeiçoasse o sistema indenizatório trabalhista, de forma a estimular a produtividade nas empresas e, ao mesmo tempo, garantir uma parcela remuneratória proporcional aos trabalhadores.

Edmo Lima de Marca destaca que:

Idealizou-se, então, um sistema que permitisse às empresas cobrir, prévia e parceladamente, a liquidação do valor da indenização por tempo de serviço, através de depósitos mensais, correspondentes a parcelas proporcionais à remuneração dos empregados. [...]

Em benefício do próprio trabalhador e do desenvolvimento sócio-econômico da nação, procurou-se, ao mesmo tempo, destinar a utilização dessa massa de recursos - constituída dos depósitos dos empregados - para o atendimento de uma das necessidades fundamentais do homem: a habitação.

Concomitantemente, cuidou-se que esses recursos fossem preservados da desvalorização da moeda, estabelecendo-se uma forma de aplicação que garantisse a rentabilidade para garantir a correção monetária e a capitalização desses valores (1972, p. 283 e 284).

Todos esses fatores levaram à elaboração do novo regime de tutela do tempo de 
serviço celetista, chamado Fundo de Garantia Tempo de Serviço, que culminou na edição da Lei 5.107 de 13 de setembro de 1966 (BRASIL). Então, em 1966, tornou-se opção do empregado a adesão a este regime ou a sua permanência no sistema estabilitário previsto na norma trabalhista, já que o novo sistema de proteção ao emprego passou a vigorar paralelamente ao sistema ate então existente.

A Lei n. 5.107/1966 (BRASIL) determinava que os empregadores depositassem, mensalmente, a quantia de $8 \%$ (oito por cento) incidente sobre a remuneração de cada empregado que optasse pelo novo regime, em conta bancária vinculada em nome do próprio empregado. Edmo Lima de Marca (1972) ressalta que há obrigatoriedade de depósito mesmo em benefício dos empregados que não tenham optado pelo novo regime, com a finalidade de garantir o eventual pagamento de uma indenização, podendo a empresa reaver esses valores nos casos em que forem rescindidos os contratos dos "não optantes", após um ano de serviço.

De toda sorte, à época discutiu-se a instituição deste regime alternativo, especialmente a possibilidade de opção pelos empregados, tendo em vista que não poderia a Lei 5.107 extinguir o sistema estabilitário. A possibilidade de exclusão do regime estabilitário trabalhista esbarraria na tradição constitucional de garantir aos empregados estabilidade no emprego e indenizações proporcionais ao tempo de serviço, já previstas nas Constituições Federais de 1937 e 1946, artigos 137 e 157, respectivamente (COSSERMELLI, 1971).

Eduardo Cossermelli (1971) destaca que, na época em que foi instituída a possibilidade de opção pelo sistema do FGTS, surgiram interpretações no sentido de que a opção pelo FGTS pelo empregado autorizaria a sua dispensa imotivada, ainda que já tivesse mais de 10 anos de serviços prestados na empresa, anteriores à opção. $\mathrm{O}$ autor alerta que tal interpretação é contrária à finalidade da própria lei e destaca:

É de lembrar o debate público, o interesse despertado, a manifestação de muitos, o insurgimento sindical, quando se pretendeu estabelecer o "sistema" de Fundo, com perda da estabilidade pretendida. Resultou que o Congresso Nacional, sensível ao problema, deu redação especial e específica ao art. $1^{\circ}$, e estampou: "para garantia do tempo de serviço, ficam mantidos os capítulos V e VII, do Título IV da CLT". (COSSERMELLI, 1971, p. 280)

Assim, segundo Eduardo Cossermelli (1971), a intenção do legislador não teria sido revogar o sistema estabilitário até então existente, violando o direito adquirido, mas apenas deferir "mais um direito" ao empregado, considerando que o "direito adquirido" ao sistema de estabilidade e indenizações por tempo de serviço não poderia ser atingido pela lei ordinária do FGTS. 
Eduardo Cossermelli esclarece que:

O que exposto já permite fixar, e fácil entender, que a opção exercitada ao abrigo do art. $1^{\circ}$, diz respeito exclusivamente ao REGIME de proteção, sempre a partir da data de opção. O optante que estava sob regime anterior de indenização aleatória, ocasional, dependente de processo judicial, de auto-sobrevivência, de continuidade da empresa, ou suas possibilidades financeiras, passou a um novo regime, no qual, mês a mês, a indenização de antiguidade é depositada em Banco, em seu nome, intocável por outrem e rentável ainda. A opção exercida foi entre dois regimes, diversos, e sempre a partir da data certa. Daí se pode concluir, que o ato de opção pelo regime do F.G.T.S, por parte do trabalhador, é restrito à forma de sua futura indenização, entre aleatória e certa, e a partir da data da opção. Ao empregador a lei desobrigou do tempo de serviço posterior à opção, exatamente porque tal empregador passou a depositar, mês a mês, o equivalente à indenização [...]. Não tem, pois, alcance retro-operante a opção firmada pelo trabalhador (1971, p. 280).

O artigo 16 da Lei 5.107/1966 comprova que foi preservado o período anterior à opção eventualmente feita pelo empregado, tendo em vista que facultou ao empregador efetuar o depósito dos valores correspondentes àquele período, in verbis:

\begin{abstract}
Art. 16 Os empregados que, na forma do art. $1^{\circ}$ optarem pelo regime desta Lei terão, na ocorrência de rescisão do contrato de trabalho, regulados os direitos relativos ao tempo de serviço anterior à opção, de acôrdo com o sistema estabelecido no Capítulo V do Título IV da CLT, calculada, porém, a indenização, para os que contem 10 (dez) ou mais anos de serviço, na base prevista no artigo 497 da mesma CLT. Pelo tempo de serviço posterior à opção, terão assegurados os direitos decorrentes desta Lei.

$\S 1^{\circ}$ - O valor da indenização, correspondente ao tempo de serviço anterior à opção, será complementado pela emprêsa, mediante depósito na conta vinculada do empregado.

$\S 2^{\circ}$ - É facultado à emprêsa, a qualquer tempo, desobrigar-se da responsabilidade da indenização relativa ao tempo de serviço anterior à opção depositando na conta vinculada do empregado o valor correspondente na data do depósito. (BRASIL, 1966)
\end{abstract}

Esclarecidas as questões iniciais em relação à opção pelo regime dos depósitos do FGTS, quando instituído, e atualmente generalizados no ordenamento jurídico brasileiro, importante analisar como foram gerenciados os depósitos que passaram a ser feitos sob essa nova sistemática.

A sistemática introduzida à época determinou que os depósitos fossem feitos nas agências bancárias, de forma a facilitar o acesso a tais parcelas pelos empregados, e, ao mesmo tempo, facilitar o gerenciamento dos depósitos pelos empregadores. À época, a gestão do fundo e a aplicação dos recursos provenientes dos valores depositados era do Banco Nacional de Habitação, criado pelo governo em 1964, através da Lei n. 4.380 (destaca-se que atualmente a gestão do fundo é feita pela Caixa Econômica Federal). Sobre a gestão dos valores, Edson Lima Marca destaca que, à época, "sendo o BNH o gestor do Fundo, foi possível, uma vez que já vigorava o princípio da correção monetária nas aplicações do sistema financeiro da habitação, 
assegurar-se a manutenção do poder aquisitivo dos valores das contas vinculadas” (1972, p. 285 e 286).

Explica, ainda, que as contas passaram a ser trimestralmente acrescidas da correção monetária na forma e pelos critérios adotados pelo sistema financeiro de habitação, além de capitalizarem juros à taxa de 3\% (três por cento) ao ano (MARCA, 1972). Essa capitalização tem por finalidade garantir que o valor total dos depósitos não seja inferior ao do valor devido em decorrência da indenização do regime tradicional celetista, podendo até mesmo superá-lo.

O novo sistema permitiu que os empregados tivessem direito aos valores depositados com juros e correção monetária, ainda que sejam dispensados por justa causa, na forma prevista na lei, ao contrário do antigo regime, que somente permitia o recebimento da indenização a partir de um ano de serviços prestados na empresa e desde que não ocorresse a dispensa por justa causa. Ainda que dispensados por justa causa, no novo regime, os empregados receberão os valores depositados com a incidência de juros e correção, nas hipóteses autorizadas em lei.

Do ponto de vista do custeio do sistema habitacional, a instituição do sistema do FGTS foi extremamente importante para o desenvolvimento do País, nesse sentido Edson Lima Marca destaca os benefícios que essa fonte trouxe ao Plano Nacional de Habitação:

\begin{abstract}
Incentivou-se a indústria da construção civil, permitindo-se, simultaneamente, a intensificação do aperfeiçoamento da mão-de-obra, tornando o processo de produção de habitações um meio de ativar o desenvolvimento econômico. Com o incremento do Plano Nacional da Habitação, passou-se a aplicar os recursos provenientes do Fundo para financiar o Planejamento do Desenvolvimento Local Integrado e o sistema de saneamento básico, que constitui a infra-estrutura das comunidades urbanas ou rurais, proporcionando melhores condições de habitabilidade. Igualmente, esses recursos deram início ao efetivo financiamento às indústrias de materiais de construção, possibilitando a modernização das já existentes, bem como a implantação de novas. Igualmente, esses recursos deram início ao efetivo financiamento às indústrias de materiais de construção, possibilitando a modernização das já existentes, bem como a implantação de novas. Promoveu-se a criação de programas complementares, com a finalidade de possibilitar a implantação do Plano Nacional de Habitação. A importância do FGTS na economia brasileira, traduz-se, portanto, na criação de recursos induzidos e livres, com o restabelecimento de poupança voluntária, que passou a constituir também um suporte financeiro do BNH, no aumento da oferta de empregos, no aceleramento da construção de habitações e, em consequência, na criação de novos recursos para o Fundo. (1971, p. 287).
\end{abstract}

Portanto, a criação do sistema do FGTS teve dupla finalidade: assegurar as indenizações devidas aos trabalhadores e, ao mesmo tempo, obter recursos para incentivar o sistema nacional de habitação, ressaltando-se que a Emenda Constitucional n. 26 incluiu a moradia como direito fundamental, no artigo $6^{\circ}$ (GUIMARÃES, 2000). 
O sistema do FGTS foi generalizado no Brasil com o advento da Constituição da República de 1988, que determinou a obrigatoriedade do regime para todos os trabalhadores celetistas, em seu rol de direitos sociais, nos seguintes termos: “Art. $7^{\circ}$ São direitos dos trabalhadores urbanos e rurais, além de outros que visem à melhoria de sua condição social: [...], III - fundo de garantia do tempo de serviço" (BRASIL).

A partir de 1988, então, findou-se a discussão sobre a opção pelo regime do FGTS, estando todos os trabalhadores vinculados a esse regime daí em diante, ressalvado o direito adquirido daqueles que haviam alcançado a estabilidade no emprego antes da promulgação da Carta Magna. O FGTS foi regulamentado, desde a sua instituição, pelas seguintes leis básicas:

[...] n. 5.107/66, que vigeu até a Constituição de 1988, com a qual, em grande parte, se tornou incompatível; a de n. 7.839, de 12 de outubro de 1989, destinada a adaptar sua disciplina ordinária às novas regras constitucionais, e a de n. 8.036, de 12 de maio de 1990, que reequacionou essa disciplina, estando, hoje, em vigor.

A cada uma dessas leis correspondeu um Regulamento, de grande importância pelo detalhamento de sua aplicação, correspondendo aos Decretos 59.820, de 20 de dezembro de 1966; 98.813, de 10 de janeiro de 1990, e 99.684, de 8 de novembro de 1990. (RODRIGUES, 1997, p. 490).

A Lei n. 8036/90 regulamenta o sistema do FGTS atualmente no Brasil. Nos termos do artigo 15 da Lei 8036/90 (BRASIL), todos os empregadores devem depositar compulsoriamente em conta vinculada, até o dia 7 de cada mês, o equivalente a $8 \%$ (oito por cento) sobre a remuneração paga ou devida ao trabalhador, relativas ao mês anterior. Destaca- se que estão incluídas nesse valor as somas de que tratam os artigos 457 e 458 da CLT (BRASIL), ou seja, todas as parcelas de natureza salarial, incluindo a gratificação natalina.

As hipóteses de saque dos depósitos do FGTS foram, notadamente, ampliadas na atualidade pelo conteúdo do artigo 20 da Lei 8036, de 11 de maio de 1990 (BRASIL).

Importante destacar que o artigo 18 da Lei 8.036/90 (BRASIL) determina o pagamento da chamada "multa fundiária", correspondente a $40 \%$ (quarenta por cento) do valor depositado ao longo do pacto na conta vinculada em nome do empregado, atualizado monetariamente e com juros, sendo o valor da multa reduzido para $20 \%$ (vinte por cento) nos casos em que a rescisão contratual ocorrer em decorrência de culpa recíproca das partes ou nos casos de força maior.

Destaca-se que a multa de $40 \%$ do FGTS é tida como provisória, tendo em vista que o artigo 10 do Ato das Disposições Constitucionais Transitórias determina que o pagamento da multa deverá ocorrer até a edição da Lei Complementar a que se refere o artigo $7^{\circ}$, inciso I 
da $\mathrm{CR} / 88$, que determina a proteção contra dispensa arbitrária ou sem justa causa, na forma da lei, que deverá prever, dentre outros direitos, a indenização compensatória (OLIVEIRA, 2004). Considerando que a lei complementar não foi editada, a aplicação da multa fundiária perdura até os dias de hoje.

Importante ressaltar também que, no ano de 2001, foi editada a Lei Complementar n. 110, instituindo duas espécies de contribuições sociais ao FGTS, segundo Vittorio Cassone (2001, p. 629):

I - devida pelos empregadores em casos de despedimento de empregado sem justa causa, à alíquota de dez por cento sobre o montante de todos os depósitos devidos, referentes ao FGTS, durante a vigência do contrato de trabalho, acrescido das remunerações aplicáveis às contas vinculadas $\left(\operatorname{art} .1^{\circ}\right)$; II - à alíquota de cinco décimos por cento sobre a remuneração devida no mês anterior, a cada trabalhador, incluídas a parcela de que trata o art. 15 da Lei n. 8.036 de 11.05 .1990 (art. $2^{\circ}$ ).

Foram, portanto, adicionados aos depósitos mensais feitos pelos empregados, a título de contribuição social, o importe de $0,5 \%$ (cinco décimos por cento), além do importe de $10 \%$ (dez por cento) nos casos em que for paga a multa de $40 \%$ (quarenta por cento) já existente para as hipóteses de dispensa imotivada.

O adicional de $10 \%$ acrescido com a Lei Complementar foi instituído com o objetivo de obtenção de recursos para suprir o déficit decorrente dos expurgos inflacionários dos Planos Verão e Collor, de 1989 e 1990, respectivamente.

Vittorio Cassone (2001) afirma que, se tratando o FGTS de direito social trabalhista, que deve ser garantido pelo empregador, ao efetuar os depósitos legais, não poderia esse "quantum indenizatório" ser visto como uma verba de natureza tributária. Ademais, analisando especialmente a correção monetária aplicável aos depósitos do FGTS, não se trata de um "plus", mas sim de uma simples reposição nominal do valor da moeda.

Afirma, dessa forma, que a natureza jurídica dos depósitos é de cunho social trabalhista (CASSONE, 2001). No mesmo sentido, Carlos Alfredo Cruz Guimarães (2000) afirma que a natureza jurídica do FGTS, pacificada pelo Supremo Tribunal Federal, é de contribuição social.

Com o objetivo de manter atualizado o poder aquisitivo do Fundo, foram mantidas as atualizações dos valores através da correção monetária e da capitalização dos juros a taxa de $3 \%$ ao ano, conforme disciplinam os artigos $2^{\circ}$ e 13 da Lei 8.036/90:

Art. $2^{\circ}$ O FGTS é constituído pelos saldos das contas vinculadas a que se refere esta Lei e outros recursos a ele incorporados, devendo ser aplicados com atualização monetária e juros, de modo a assegurar a cobertura de suas obrigações. $\S 1^{\circ}$ Constituem recursos incorporados ao FGTS, nos termos do caput deste artigo: $[\ldots]$ 
d) multas, correção monetária e juros moratórios devidos;

Art. 13. Os depósitos efetuados nas contas vinculadas serão corrigidos monetariamente com base nos parâmetros fixados para atualização dos saldos dos depósitos de poupança e capitalizarão juros de 3\% (três por cento) ao ano.

[...]

$\S 2^{\circ}$ Após a centralização das contas vinculadas, na Caixa Econômica Federal, a atualização monetária e a capitalização de juros correrão à conta do Fundo e o respectivo crédito será efetuado na conta vinculada, no dia 10 (dez) de cada mês, com base no saldo existente no dia 10 (dez) do mês anterior ou no $1^{\circ}$ (primeiro) dia útil subseqüente, caso o dia 10 (dez) seja feriado bancário, deduzidos os saques ocorridos no período. (BRASIL)

Ocorre que, a partir do ano de 1999 o FGTS, que deve ser corrigido pelos parâmetros fixados para atualização dos depósitos de poupança (a Taxa Referencial - TR) mais 3\% (três por cento) ao ano, sofreu enorme desvalorização, trazendo prejuízos ao fundo em questão, ao trabalhador e à sociedade em geral, posto que é instituto de cunho social trabalhista e fomentador do sistema da habitação, conforme a seguir analisado.

\section{A REGRA DE ATUALIZAÇÃO DO FGTS: ANÁLISE DA TAXA REFERENCIAL}

A Taxa Referencial (TR) nasceu da Lei 8.137, de 31/03/1991, ficando conhecida como Plano Collor II, tendo como objetivo estabelecer regras para a desindexação da economia, sendo calculada:

[...] a partir da remuneração mensal média dos CDB/RDB emitidos a taxas de mercado prefixadas, com prazo de 30 a 35 dias corridos, inclusive com base em informações prestadas pelas instituições integrantes da amostra de que trata o art. $1^{\circ}$, na forma a ser determinada pelo Banco Central do Brasil. (BRASIL)

Os Certificados de Depósitos Bancários (CDB), que constituem a referência primordial da TBF, são títulos nominativos emitidos pelas instituições financeiras e lançados no mercado com o objetivo de captar recursos, o que os torna absolutamente vulneráveis à variação da taxa básica de juros - SELIC. Sendo assim, aplicando a TBF como redutor da TR temos uma taxa próxima de zero ou muito alto, em alguns períodos, dependendo da saúde da economia brasileira.

Por tal motivo, nos períodos apresentados nas ações que discutem o FGTS, entre 1999 e 2013, o índice atingiu níveis muito pequenos, pelo fato de diminuição da Selic.

A legislação que trata sobre a elaboração da TR, evidenciando sua metodologia de cálculo, é a Resolução 3.354/2006 do Bacen. O exame dos normativos concernentes à TR revela que se trata de um indicador econômico de juros, não de um índice de correção monetária, pois 
o que define a TR não é a variação dos preços em geral, mas sim o preço do dinheiro no mercado financeiro.

Com isso, a adoção da TR para atualização econômica dos saldos das contas vinculadas do FGTS tem se revelado prejudicial aos trabalhadores na medida em que ela tem sido seguidamente superada pelos índices oficiais de inflação como o INPC e o IPCA-e, penalizando a essência social do FGTS por sua deterioração, conforme se demonstra na tabela abaixo pelos percentuais disponíveis no Instituto Brasileiro de Geografia e Estatística - IBGE (BRASIL):

\begin{tabular}{|c|c|c|c|c|c|c|c|}
\hline ANO & & TR & & INPC & & IPCA-E & \\
\hline & 1999 & & $5,7295 \%$ & & $8,4300 \%$ & & $8,9200 \%$ \\
\hline & 2000 & & $2,0960 \%$ & & $5,2700 \%$ & & $6,0300 \%$ \\
\hline & 2001 & & $2,2852 \%$ & & $9,4400 \%$ & & $7,5100 \%$ \\
\hline & 2002 & & $2.8023 \%$ & & $14,7400 \%$ & & $11,9800 \%$ \\
\hline & 2003 & I & $4,6458 \%$ & & $10,3800 \%$ & & $9,8600 \%$ \\
\hline & 2004 & & $1,8184 \%$ & & $6,1300 \%$ & & $7,5300 \%$ \\
\hline & 2005 & & $2,8335 \%$ & & $5,0500 \%$ & & $5,8700 \%$ \\
\hline & 2006 & & $2,0377 \%$ & & $2,8100 \%$ & & $2,9500 \%$ \\
\hline & 2007 & & $1,4452 \%$ & & $5,1500 \%$ & & $4,3600 \%$ \\
\hline & 2008 & & $1,6348 \%$ & & $6,4800 \%$ & & $6,1000 \%$ \\
\hline & 2009 & & $0,7090 \%$ & & $4,1100 \%$ & & $4,1800 \%$ \\
\hline & 2010 & & $0,6887 \%$ & & $6,4600 \%$ & & $5,7900 \%$ \\
\hline & 2011 & & $1,2079 \%$ & & $6,0700 \%$ & & $6,5500 \%$ \\
\hline & 2012 & & $0,2897 \%$ & & $6,1900 \%$ & & $5,7700 \%$ \\
\hline & 2013 & & $0,1910 \%$ & & $5,5600 \%$ & & $5,8400 \%$ \\
\hline
\end{tabular}

Como destacado na disposição do caput do artigo $7^{\circ}$ da Constituição da República (BRASIL), o FGTS é um direito do trabalhador que visa à melhoria de sua condição social e a ausência de uma taxa de atualização monetária que se mostre capaz de manter o poder de compra da moeda, nos casos do saldo da conta vinculada do FGTS, é uma nítida afronta ao sistema jurídico vigente.

Luiz Antônio Scavone Junior (2011) explica o que é a correção monetária expondo a impropriedade da utilização da TR como tal, verbis: 
A correção monetária não é um plus, mas simples manutenção do valor de compra pela variação dos preços na economia, ou seja, é um índice que reflete o acréscimo (inflação) ou decréscimo (deflação) dos preços do mercado.

[...] Convém ressaltar que os índices de correção monetária refletem os aumentos e diminuições dos preços na economia, cujas causa são: a) existência de muitos ou poucos compradores dispostos a pagar por um produto ou serviço, cuja oferta, no primeiro caso, não consegui satisfazer; b) aumento ou diminuição dos custos das empresas, que são repassados para os consumidores e clientes.

Os juros, por outro lado, são remuneração de capital, frutos civis.

Assim, representam um acréscimo real ao valor inicial, ao revés da correção monetária. Os juros são interesses ou lucros que a pessoa tira da inversão de seus capitais ou dinheiros, ou que recebe do devedor. (SCAVONE JUNIOR, 2011, p. 411)

E assim finaliza Scavone Junior sua explicação quanto ao tema:

É possível afirmar, portanto, que a TR nada tem a ver com reposição do poder de compra da moeda. É verdadeiramente mensurada pela taxa média para na captação de recursos de uma só modalidade de investimento (CDB - Certificado de Depósito Bancário). Aliás, abarca apenas uma pequena parte do mercado financeiro, o que se afirma na exata medida em que os CDB's existem no Sistema financeiro representam menos de $2,5 \%$ do total de ativos em estoque.

Como se depreende, acorde com a Resolução 3354/2006, do Banco Central do Brasil (e anterior Resolução 2,809, de 21 de dezembro de 2000, revogada pela atual), a TR é claramente uma taxa de juros e não de correção, não refletindo, de forma alguma, os preços na economia, inferência que se extrai da análise da sistemática de sua apuração, que toma por base os Certificados de Depósitos Bancários (CDB's). (SCAVONE JUNIOR, 2011, p. 415)

Portanto, a atualização do saldo das contas vinculadas do FGTS, de fato, se mostra imprópria a ser atualizada por tal taxa.

Ao não atualizar os valores do saldo de acordo com um índice que reflita a inflação, o dinheiro depositado - e que não pode ser sacado a qualquer pretexto - perde o seu poder de compra, corroendo-se pelo decurso temporal, assim, a correção pela TR impede que a própria Lei 8.036/90 atinja a sua finalidade de auxiliar o trabalhador, uma vez que os descontos mensais realizados e depositados em conta vinculada de instituição financeira (atualmente Caixa Econômica Federal) não foram (e não são) corretamente atualizados, havendo clara violação ao art. $2^{\circ}$ e art. $9^{\circ}, \S 2^{\circ}$ da Lei $8.036 / 90^{1}$, que determinam a necessidade de atualização monetária para a manutenção do poder aquisitivo do trabalhador.

Há, também, ofensa direta ao art. $5^{\circ}$, XXII, da Constituição da República de $88^{2}$, que garante o direito de propriedade. Como o saldo do FGTS integra o patrimônio do trabalhador, a sua não correção implica, por óbvio, na redução da sua propriedade, não obstante a incidência da Lei $\mathrm{n}^{\circ}$ 8.036/90 garantindo o direito à atualização, nos termos do art. $2^{\circ}$, caput, § $1^{\mathrm{o}}$, alínea $\mathrm{b}$.

Importante destacar que não se está questionando a legalidade da TR como índice, porque prevista na Lei 8.036/90, porém afirmando sua impropriedade e a necessidade de 
aplicação de um fator capaz de possibilitar a correção monetária dos depósitos do FGTS conforme preceitos constitucionais, sociais e de proteção ao trabalhador.

\subsection{Julgados Sobre O Tema Em Discussão}

A jurisprudência é farta neste assunto, no sentido de que a TR não é índice de correção de acordo com os julgados abaixo analisados.

O Supremo Tribunal Federal (STF), no julgamento da ADI 493-DF (BRASIL), deixou consignado que "a taxa referencial (TR) não é índice de correção monetária, pois, refletindo as variações do custo primário da captação dos depósitos prazo fixo, não constitui índice que reflita a variação do poder aquisitivo da moeda". No mesmo sentido, a correção pretendida "não é acréscimo, constituindo imperativo econômico, ético e jurídico, destinada a manter o equilíbrio das relações, e evitar o enriquecimento sem causa, razão porque sua incidência independe de lei específica" (BRASIL). E outros julgados, tais como o REsp 46.372-SP, de Relatoria do Min. Waldemar Zveiter, REsp 52.961-RJ, Relator Pedro Acioli, REsp 75.575-SP, Relator José de Jesus Filho, entre outros.

Interessante deixar consignado o entendimento do Ministro Athos Gusmão Carneiro no sentido de informar que: "Quem paga com correção não paga mais do que deve, mantendo o valor liberatório da moeda. Quem recebe sem correção não recebeu aquilo que por lei ou contrato lhe era devido; recebeu, quiçá, quantia meramente simbólica, de valor liberatório aviltado pela inflação.” (BRASIL)

\footnotetext{
${ }^{1}$ Art. $2^{\circ}$ O FGTS é constituído pelos saldos das contas vinculadas a que se refere esta lei e outros recursos a ele incorporados, devendo ser aplicados com atualização monetária e juros, de modo a assegurar a cobertura de suas obrigações. Art. $9^{\circ}(\ldots) \S$ $2^{\circ}$ Os recursos do FGTS deverão ser aplicados em habitação, saneamento básico e infra-estrutura urbana. As disponibilidades financeiras devem ser mantidas em volume que satisfaça as condições de liquidez e remuneração mínima necessária à preservação do poder aquisitivo da moeda.

2 Art. $5^{\circ}$ Todos são iguais perante a lei, sem distinção de qualquer natureza, garantindo-se aos brasileiros e aos estrangeiros residentes no País a inviolabilidade do direito à vida, à liberdade, à igualdade, à segurança e à propriedade, nos termos seguintes: (...) XXII - é garantido o direito de propriedade;
} 
Por essa natureza jurídica da TR diversa de atualização da moeda, o STF na Ação Direta de Inconstitucionalidade, ADI 4.357 de 15/12/2009, rechaçou a TR como índice de correção monetária para o caso de pagamento da dívida pública por precatório. A decisão foi proferida nos seguintes termos:

Concluindo o julgamento, o Tribunal, por maioria e nos termos do voto, ora reajustado, do Ministro Luiz Fux (Relator), resolveu a questão de ordem nos seguintes termos: 1) - modular os efeitos para que se dê sobrevida ao regime especial de pagamento de precatórios, instituído pela Emenda Constitucional $n^{\circ} 62 / 2009$, por 5 (cinco) exercícios financeiros a contar de primeiro de janeiro de 2016 ; 2) - conferir eficácia prospectiva à declaração de inconstitucionalidade dos seguintes aspectos da ADI, fixando como marco inicial a data de conclusão do julgamento da presente questão de ordem (25.03.2015) e mantendo-se válidos os precatórios expedidos ou pagos até esta data, a saber: 2.1.) fica mantida a aplicação do índice oficial de remuneração básica da caderneta de poupança (TR), nos termos da Emenda Constitucional $\mathrm{n}^{\mathrm{o}}$ 62/2009, até 25.03.2015, data após a qual (i) os créditos em precatórios deverão ser corrigidos pelo Índice de Preços ao Consumidor Amplo Especial (IPCA-E) e (ii) os precatórios tributários deverão observar os mesmos critérios pelos quais a Fazenda Pública corrige seus créditos tributários; e 2.2.) ficam resguardados os precatórios expedidos, no âmbito da administração pública federal, com base nos arts. 27 das Leis $\mathrm{n}^{\circ} 12.919 / 13$ e Lei $\mathrm{n}^{\mathrm{o}} 13.080 / 15$, que fixam o IPCA-E como índice de correção monetária; 3) - quanto às formas alternativas de pagamento previstas no regime especial: 3.1) consideram-se válidas as compensações, os leilões e os pagamentos à vista por ordem crescente de crédito previstos na Emenda Constitucional no 62/2009, desde que realizados até 25.03.2015, data a partir da qual não será possível a quitação de precatórios por tais modalidades; 3.2 ) fica mantida a possibilidade de realização de acordos diretos, observada a ordem de preferência dos credores e de acordo com lei própria da entidade devedora, com redução máxima de

$40 \%$ do valor do crédito atualizado; 4) - durante o período fixado no item 1 acima, ficam mantidas a vinculação de percentuais mínimos da receita corrente líquida ao pagamento dos precatórios (art. 97, §10, do ADCT), bem como as sanções para o caso de não liberação tempestiva dos recursos destinados ao pagamento de precatórios (art. 97, § 10, do ADCT); 5) - delegação de competência ao Conselho Nacional de Justiça para que considere a apresentação de proposta normativa que discipline (i) a utilização compulsória de $50 \%$ dos recursos da conta de depósitos judiciais tributários para o pagamento de precatórios e (ii) a possibilidade de compensação de precatórios vencidos, próprios ou de terceiros, com o estoque de créditos inscritos em dívida ativa até 25.03.2015, por opção do credor do precatório, e 6) - atribuição de competência ao Conselho Nacional de Justiça para que monitore e supervisione o pagamento dos precatórios pelos entes públicos na forma da presente decisão, vencido o Ministro Marco Aurélio, que não modulava os efeitos da decisão, e, em menor extensão, a Ministra Rosa Weber, que fixava como marco inicial a data do julgamento da ação direta de inconstitucionalidade. Reajustaram seus votos os Ministros Roberto Barroso, Dias Toffoli e Gilmar Mendes. Presidência do Ministro Ricardo Lewandowski. Plenário, 25.03.2015. (BRASIL) (grifos nossos)

O STF entendeu que a TR não é índice de atualização monetária, ou seja, a decisão do STF dá suporte e base à tese de integridade da correção dos depósitos do FGTS para outro índice que, no caso, por coerência e analogia, deve ser aplicado o IPCA-E. Tanto que as leis 12.919/2013 e 13.080/2015, que dispõem sobre as diretrizes para elaboração e execução da 
Lei Orçamentária para os anos de 2014 e 2015, respectivamente, já estabeleceram esta disposição ao mencionar a redação a seguir transcrita, na ordem de sua promulgação, vejamos:

Art. 27. A atualização monetária dos precatórios, determinada no $§ 12$ do art. 100 da Constituição Federal, inclusive em relação às causas trabalhistas, previdenciárias e de acidente do trabalho, observará, no exercício de 2014, a variação do Índice Nacional de Preços ao Consumidor Amplo - Especial - IPCA-E do IBGE. (BRASIL)

Art. 27. A atualização monetária dos precatórios, determinada no $\S 12$ do art. 100 da Constituição Federal, bem como das requisições de pequeno valor expedidas no ano de 2015, inclusive em relação às causas trabalhistas, previdenciárias e de acidente do trabalho, observará, no exercício de 2015, a variação do Índice Nacional de Preços ao Consumidor Amplo - Especial - IPCA-E do IBGE, da data do cálculo exequendo até o seu efetivo depósito. (BRASIL)

A aplicação desta decisão é nítida expressão de justiça àqueles que tem a TR como fator de correção monetária, francamente solapada pela inflação, sem conferir a natureza de índice de correção eficaz. Em interessante decisão proferida nos autos da ação 327988.2013.4.01.3810, em trâmite na Subseção Judiciária de Pouso Alegre/MG da Justiça Federal, em 16/01/2014, a aplicação da TR nas contas vinculadas do FGTS foi analisada pelo juízo nos seguintes termos:

Em resumo, a remuneração básica das cadernetas de poupança, que desde sua criação no final dos anos 60 tinha sido realizada por algum índice de inflação passada, foi substituída pela TR por força da lei 8.177/91, num movimento de desindexação da economia, inicialmente substituindo a inflação passada pela previsão de inflação futura - objetivo do cálculo da TR nos seus primórdios - e, posteriormente, desvinculando-se totalmente também da inflação futura, pelas sucessivas metodologias de cálculo desse índice financeiro.

Se já quando de sua introdução a TR não mais podia ser utilizada como índice de correção monetária (pois mesmo como "previsão de inflação futura" ela jamais pôde antecipar, de forma matematicamente precisa, essa inflação e, portanto, não podia ser utilizada como tal) e isso foi reconhecido pelo E. STF no julgamento da ADIN 4930/DF, no último sesquidecênio ela se desvinculou totalmente de qualquer correlação com a inflação passada ou futura, não podendo jamais servir como índice de correção monetária e de manutenção do valor real de direitos e obrigações, como reconhecido pelo E. STF nos recentes julgamentos das ADI 4357/DF, ADI 4372/DF, ADI 4400/DF, ADI 4425/DF, que afastaram a utilização da TR para correção das dívidas judiciais como estabelecido na EC 62/09 e na lei 11960/09.

Há dois importantes pontos a se observar.

Em primeiro lugar, a metodologia da TR fixada no art. $1^{\circ}$ da lei 8.177/91 é ampla o suficiente para permitir que sucessivos e distintos cálculos normatizados pelas resoluções do CMN sejam consideradas válidas, pois em nenhum momento a lei 8.177/91 estabelece a obrigatoriedade de a TR se vincular a uma "previsão de inflação futura" ou algo semelhante - apesar de que esse era seu fundamento do ponto de vista estritamente econômico, quando da publicação da lei 8.177/91.

Em segundo lugar, as alterações realizadas no cálculo da TR e que finalizaram por reduzi-la a algo próximo de zero, tiveram como fundamento o fato de que as cadernetas de poupanca e as demais aplicacões financeiras são portáveis. intercambiáveis, concorrem entre si pelos recursos dos aplicadores: não há nenhuma ilegitimidade ou invalidade evidente em reduzir a remuneração básica da poupança a percentuais ínfimos, pois o poupador pode, a qualquer tempo, retirar seus recursos da caderneta de poupança e colocá-los em outra aplicação financeira, se não 
estiver satisfeito. Além disso, as cadernetas de poupança podem ser sacadas a qualquer tempo e rendem mensalmente, são típicas aplicações de curtíssimo prazo, que permitem esse livre trânsito de recursos, se a rentabilidade ficar a desejar.

Isto é, para a caderneta de poupança, a TR calculada da forma atual não é inválida nem ilegítima.

Mas tais características de livre portabilidade, de curtíssimo prazo e de facultatividade da poupanca são exatamente opostas às características do FGTS, como já analisado anteriormente. (BRASIL) (grifos nossos)

Dessa forma, a aplicação da TR para as contas vinculadas do FGTS se mostra, notadamente, uma perda ao trabalhador, uma perda social.

Importante trazer à baila substancial análise realizada pelo Juiz Federal Substituto,

Diego Viegas Véras, quando prolator da sentença proferida no processo $\mathrm{n}^{\circ}$ 500953335.2013.404.7002/PR, em 15-01-2014, ao dispor que:

Há que se verificar quais dos programas instituídos pelo Governo Federal e operacionalizados pela CEF, quer seja de financiamento estudantil, habitacional ou de infraestrutura em que há cobrança de juros de $3 \%$ ao ano. Segundo informações do sítio eletrônico (www.cef.gov.br), a taxa cobrada no programa 'Minha casa melhor' é de 5\% ao ano, enquanto do programa 'Minha casa minha vida' vão de 5\% a 8,66\% ao ano. Não há, pois, qualquer paralelismo quanto trata-se de taxa de juros aplicadas. Ou seja, no sistema atual o governo busca implementar projetos subsidiados às custas da baixa remuneracão e quase nula atualizacão monetária dos saldos das contas do Fundo de Garantia. Ou seja, inexiste, no sistema atual. qualquer remuneracão aos saldos das contas do FGTS. Pelo contrário, pois os juros de $3 \%$ ao ano sequer são suficientes para repor a desvalorização da moeda no período.

Não se desconhece que o FGTS possui relevante papel social na prática das políticas públicas no Brasil, mas não há que se olvidar que historicamente sua criação teve por objeto dar ao trabalhador estabilidade no trabalho e alguma segurança financeira em caso de demissão sem justa causa, em substituição à antiga estabilidade decenal. Os valores depositados à sua ordem no FGTS, ainda que realizados pelo empregador, pertencem ao empregado, que não obstante não possa fazer livre movimentação de sua conta, é seu titular e destinatário final. O saldo do FGTS pode ser sacado, de acordo com o art. 20, inciso V, da Lei 8.039/90, para ser utilizado como pagamento de parte das prestações decorrentes de financiamento habitacional concedido no âmbito do Sistema Financeiro de Habitação. Vemos, portanto, a hipótese absurda de que o trabalhador, tendo o saldo da sua conta de FGTS corroído pela inflacão, não dispor do suficiente para adquirir a casa própria, de forma a necessitar firmar contrato pelo SFH (o qual foi financiado às suas expensas), para pagar juros muito superiores àqueles com os quais foi remunerado. $O$ dinheiro que lhe foi subtraído pela má remuneracão de sua conta, então, deverá ser tomado emprestado daquele que o subtraiu, mediante pagamento de juros.

(BRASIL) (grifos nossos)

Verifica-se, pois, que os recursos oriundos dos depósitos do FGTS são utilizados para a efetivação de políticas públicas, fato é que os juros aplicados às contas do FGTS são de 3\% ao ano, enquanto os juros dos programas do Governo são superiores a $5 \%$ (5\% a 8,66\% ao ano) isto porque seu viés é social e como sentenciou o magistrado: "no sistema atual o governo busca implementar projetos subsidiados às custas da baixa remuneração e quase nula 
atualização monetária dos saldos das contas do Fundo de Garantia” (BRASIL), não se mostrando a TR eficaz e capaz de gerar a atualização monetária prevista na própria Lei $\mathrm{n}^{\circ}$ $8.036 / 90$, de forma a ofender o direito de propriedade dos trabalhadores que são os destinatários dos recursos depositados:

Sendo assim a TR não reflete a desvalorização da moeda como se pode esperar de um índice de correção monetária. Não se trata de índice econômico, que reflete a variação dos preços na economia, mas de índice financeiro, que espelha a taxa de juros (taxas pagas pelos CDB's - Certificados de Depósitos Bancários). (SCAVONE JUNIOR, 2011, p. 410)

Passamos, então, à análise da propositura de ações revisionais dos saldos do FGTS e das possíveis decisões que podem ser dadas a estes casos.

\title{
3. A PROPOSITURA DE AÇÕES REVISIONAIS E POTENCIAIS DECISÕES SOBRE OS PEDIDOS DE ATUALIZAÇÃO DO FGTS
}

Segundo Luiz Edgar Ferraz de Oliveira (2004), o direito de postular ação judicial objetivando o ressarcimento das perdas monetárias existe desde que o governo suprimiu por lei a correção monetária dos depósitos através dos Planos Bresser (1989) e Collor (1990). O Autor destaca que:

\begin{abstract}
Esse direito de ação, aliás, tanto existia que foi exercitado por várias pessoas trabalhadores, sindicatos, etc. - perante a Justiça Federal, a cujas decisões acudiu o Supremo Tribunal Federal dando o respaldo constitucional, o que fez o governo federal votar a Lei Complementar 110 para regulamentar as restituições determinadas pela Justiça. As decisões formaram, assim, a occasio legis que influíram na elaboração do projeto de lei. Não foi atitude magnânima do governo. O Judiciário declarou a existência do direito adquirido e a instância suprema o confirmou, selando a necessidade do governo tomar uma atitude social atinente a solucionar os conflitos extrajudicialmente, sabendo que judicialmente as causas eram perdidas. [...] Ao invés de cumpri-las por precatórios, ou transações, com processos dispendiosos às custas do erário público, o governo agiu com lógica, que foi levar o projeto de lei à votação no Congresso Nacional com intuito apenas de regulamentar uma situação jurídica referente ao modo de restituição dos valores. (2004, p. 32).
\end{abstract}

Nesse sentido, Oliveira (2004) destaca que a responsabilidade pela desatualização dos depósitos do FGTS é do Estado e, por isso, não tem relação com a figura do empregador que, inclusive, caso seja suscitado, pode invocar a hipótese de "factum principis", já que o dano foi originado pela ação do Estado. Afirma que,

Para casos semelhantes, quando o dano tiver origem em ato praticado pelo Estado, caberá ao juiz fazer a analogia da lei e declarar a responsabilidade do erário público. É evidente que dependerá da iniciativa da parte invocar o argumento, mas, uma vez invocado, deverá verificar a questão competencial em primeiro lugar. O estado não pode ficar isento de responsabilidades, sobretudo quando fere direitos adquiridos de terceiros com os seus atos de legislação, competindo ao juiz aplicar o disposto no 
artigo $37, \S 6^{\circ}$, da $\mathrm{CF}$. É certo que os prejuízos em debate decorreram de atos da política macroeconômica, onde se presume a boa-fé dos governantes, mas também é certo que a Constituição Federal proibia a votação e promulgação de leis infringentes dos direitos adquiridos e dos atos jurídicos perfeitos, o que não foi respeitado pelo Executivo e nem pelo Legislativo. Os empregadores não tiveram participação direta ou indireta nos planos econômicos. Sua obrigação era recolher as contribuições ao FGTS, mês a mês, e de pagar a multa de $40 \%$ sobre o montante dos depósitos devidos no curso do contrato. A responsabilidade de atualizar os valores e de aplicar os juros era - e é - da Caixa Econômica Federal. Portanto, se o Governo deixou de atualizar os depósitos do FGTS em 16,64\% (Plano Bresser) e em 44,80\% (Plano Collor), tais atos podem ser considerados atos de príncipe. (OLIVEIRA, 2004, p. 28 e 29).

Diante do exposto, não há dúvidas acerca da legitimidade e competência para conhecimento das ações ora discutidas. O impacto das ações com o objetivo de reaver a atualização dos depósitos do FGTS por outro índice que não a TR podem ter algumas implicações no mundo fenomênico.

Primeiro, se o julgamento for pela improcedência, não haveria mudança na forma de cálculo, sendo mantida as determinações da Lei 8036/90; segundo, se o julgamento for pela procedência: poder-se-ia dar provimento pela troca da TR pelo IPCA-E, como no caso dos precatórios, mantendo a mesma semântica judiciária para casos análogos.

Porém, qual período e em qual tempo o trabalhador poderia impugnar estas perdas e pedir sua atualização ao Judiciário?

Passamos, então, à discussão de tais regras aplicáveis ao fundo social em debate, para, ao fim, apresentar qual é regra deverá ser aplicada aos direitos decorrentes das diferenças existentes nos expurgos inflacionários do FGTS.

Inicialmente, destaca-se que a prescrição pode ser aquisitiva ou extintiva. A chamada prescrição aquisitiva é “o meio de aquisição de propriedade mobiliária ou imobiliária, em decorrência do seu prolongado uso pacífico" (DELGADO, 2014, p. 249). É também chamada "usucapião".

A prescrição extintiva constitui a perda do direito de pretensão de ação em decorrência do esgotamento do lapso temporal previsto para o seu exercício em juízo. Tem-se, portanto, que o jurisdicionado não exerceu o direito de ação do qual era titular no prazo determinado e, por isso, não poderá mais exigir o cumprimento da obrigação.

Segundo Maurício Godinho Delgado, a prescrição extintiva "conceitua-se, na linha teórica expressa no art. 189 do Código Civil de 2002, como a extinção da pretensão correspondente a certo direito violado em decorrência de o titular não ter exercitado no prazo legalmente estabelecido" (2014, p. 249). A análise é feita sob a ótica do titular do direito, tendo 
em vista que o direito existe, o que se perde é a possibilidade de exigi-lo em juízo. Tratar-se-á, então, da prescrição extintiva.

A princípio, convém analisar de forma breve a regra prescricional do Direito do Trabalho, prevista na Constituição da República, especificamente no inciso XXIX do artigo $7^{\circ}$ da Constituição da República de 1988: “ação, quanto aos créditos resultantes das relações de trabalho, com prazo prescricional de cinco anos para os trabalhadores urbanos e rurais, até o limite de dois anos após a extinção do contrato de trabalho" (BRASIL).

Os trabalhadores urbanos, rurais $^{3}$ e domésticos se submetem às chamadas prescrições bienal e quinquenal previstas no inciso XXIX, do art. $7^{\circ}$, da CR/88, acima destacado. A Constituição de 1988 revogou tacitamente o artigo 11 da CLT, em sua antiga redação, que dispunha que a prescrição era de dois anos para pleitear a reparação de qualquer ato infringente de dispositivo ali contido.

A corrente interpretativa dominante sobre a regra prescricional constitucional entende que o empregado pode pleitear os seus direitos referentes aos últimos cinco anos, contados da data do ajuizamento da ação, independentemente de o contrato de trabalho ter sido extinto ou não. Este prazo prescricional de cinco anos é limitado ao prazo prescricional bienal, ou seja, extinto o contrato de trabalho, somente é possível ajuizar a ação trabalhista no prazo de dois $\operatorname{anos}^{4}$.

A regra prescricional aplicável ao Fundo de Garantia por Tempo de Serviço como parcela principal era a prescrição trintenária: respeitados os dois anos após a extinção do contrato de trabalho, poderiam ser pleiteados os últimos 30 (trinta) anos, conforme regra inserta na Lei 8036/90, art. 23, $\$ 5^{\circ}$ (BRASIL).

3

Destaca-se que a emenda constitucional 28 de 2000 unificou os prazos prescricionais do urbano e do rural. Antes da emenda somente era aplicada a prescrição bienal (art. 10, Lei 5889/73), sendo o contrato de trabalho uma causa impeditiva da prescrição. A emenda foi publicada em 29.05.2000, gerando um debate sobre os efeitos da nova regra prescricional dos rurículas, no entanto o Tribunal Superior do Trabalho já se manifestou pela irretroatividade da norma constitucional, considerando que todas as situações fático-jurídicas dos contratos dos rurais anteriores a 29.5 .2000 não se sujeitam às novas regras, estando protegidos pela antiga regra da imprescritibilidade (OJ 271 da SDI-I do TST).

4 Esse entendimento esta consubstanciado na Súmula 308 do TST, disponível em:

http://www3.tst.jus.br/jurisprudencia/Sumulas_com_indice/Sumulas_Ind_301_350.html\#SUM-308 
Entretanto, no dia 13 de novembro de 2014 o Supremo Tribunal Federal ${ }^{5}$ julgou o Recurso Extraordinário 709.212 e entendeu que a regra da Lei 8036/90 não pode subsistir. O ministro Gilmar Mendes, relator do apelo, explicou que o artigo $7^{\circ}$, inciso III, da Constituição Federal prevê expressamente o FGTS como um direito dos trabalhadores urbanos e rurais e destacou que o prazo de cinco anos aplicável aos créditos resultantes das relações de trabalho está previsto no inciso XXIX do mesmo dispositivo. Assim, de acordo com o relator, se a Constituição regula a matéria, não poderia a lei ordinária tratar o tema de outra forma, afastando a prescrição trintenária.

O relator propôs a modulação dos efeitos da decisão: para aqueles casos cujo termo inicial da prescrição - ou seja, a ausência de depósito no FGTS - ocorra após a data do julgamento, aplica-se, desde logo, o prazo de cinco anos. Por outro lado, para os casos em que o prazo prescricional já esteja em curso, aplica-se o que ocorrer primeiro: 30 anos, contados do termo inicial, ou cinco anos, a partir deste julgamento. Diante dessa decisão, a súmula $362^{6}$ do TST foi revista pelo Tribunal Superior do Trabalho.

De toda sorte, a prescrição acima analisada deve ser aplicada nos casos em que o empregado pleiteia em face do empregador, perante a Justiça do Trabalho, os depósitos do FGTS não efetuados ao longo do pacto. Aplica-se, ainda, a prescrição quinquenal nas hipóteses em que o empregado pleiteia o pagamento de parcelas salariais e, de forma acessória, a incidência do FGTS sobre as parcelas não quitadas.

No entanto, as ações em que o trabalhador pleteia o pagamento dos expurgos inflacionários decorrentes das desatualizações do FGTS, serão ajuizadas em face da Caixa Econômica Federal, porque gestora do fundo, e julgadas pela Justiça Federal, sendo incompatível a aplicação da regra prescricional trabalhista, mas aplicável a regra prescricional civil inserta no art. 189 e seguintes do Código Civil.

Isto porque não se discutem desobediência ou violações a regras trabalhistas mas sim uma atualização de seus recursos que deixou de ser aplicada. Sendo assim, haveria para o trabalhador uma prescrição, atual de 10 anos, conforme exposto no art. 205 do Código Civil

\footnotetext{
5 Disponível em: http://www.stf.jus.br/arquivo/cms/noticiaNoticiaStf/anexo/ARE709212voto.pdf

6 FGTS. PRESCRIÇÃO (nova redação) - Res. 198/2015, republicada em razão de erro material-DEJT divulgado em 12, 15 e 16.06.2015.

I - Para os casos em que a ciência da lesão ocorreu a partir de 13.11.2014, é quinquenal a prescrição do direito de reclamar contra o não-recolhimento de contribuição para o FGTS, observado o prazo de dois anos após o término do contrato; II - Para os casos em que o prazo prescricional já estava em curso em 13.11.2014, aplica-se o prazo prescricional que se consumar primeiro: trinta anos, contados do termo inicial, ou cinco anos, a partir de 13.11.2014 (STF- ARE-709212/DF).
} 
de 2002, por não haver prazo especial para tanto, à semelhança da atualização dos planos de outrora, Collor, Bresser, Verão, entre outros, conforme transcrito algumas decisões a seguir:

\begin{abstract}
RECURSO ESPECIAL REPETITIVO (ART. 543-C DO CPC) - AÇÃO DE COBRANÇA - EXPURGOS INFLACIONÁRIOS EM CADERNETA DE POUPANÇA - PLANOS BRESSER E VERÃO - PRELIMINAR - PRESCRIÇÃO VINTENÁRIA - NÃO-OCORRÊNCIA - EXIBIÇÃO DOS EXTRATOS BANCÁRIOS - INVERSÃO DO ÔNUS DA PROVA EM FAVOR DA CORRENTISTA - POSSIBILIDADE - OBRIGAÇÃO DECORRENTE DE LEI CONDICIONAMENTO OU RECUSA - INADMISSIBILIDADE - RESSALVA DEMONSTRAÇÃO DE INDÍCIOS MÍNIMOS DA EXISTÊNCIA DA CONTRATAÇẪO - INCUMBÊNCIA DO AUTOR (ART. 333, I, DO CPC) - ART. $6^{\circ}$ DA LEI DE INTRODUÇÃO AO CÓDIGO CIVIL - AUSÊNCIA DE PREQUESTIONAMENTO - INCIDÊNCIA DO ENUNCIADO N. 211/STJ - NO CASO CONCRETO, RECURSO ESPECIAL IMPROVIDO. I - Preliminar: nas ações em que se discutem os critérios de remuneração de caderneta de poupança e são postuladas as respectivas diferenças de correção monetária e dos juros remuneratórios, o prazo prescricional é de vinte anos, não transcorrido, na espécie; STJ, REsp. 1133872-PB, Relator Min. Massami Uyeda, julgado em 14/12/2011 e publicado em 28/03/2012. (BRASIL)

RECURSOS ESPECIAIS REPETITIVOS. CADERNETAS DE POUPANÇA. PLANOS ECONÔMICOS. EXPURGOS INFLACIONÁRIOS. RECURSOS REPRESENTATIVOS DE MACRO-LIDE MULTITUDINÁRIA EM AÇÕES INDIVIDUAIS MOVIDAS POR POUPADORES. JULGAMENTO NOS TERMOS DO ART. 543-C, DO CÓDIGO DE PROCESSO CIVIL. JULGAMENTO LIMITADO A MATÉRIA INFRACONSTITUCIONAL, INDEPENDENTEMENTE DE JULGAMENTO DE TEMA CONSTITUCIONAL PELO C. STF. PRELIMINAR DE SUSPENSÃO DO JULGAMENTO AFASTADA. CONSOLIDAÇÃO DE ORIENTAÇÃO JURISPRUDENCIAL FIRMADA EM INÚMEROS PRECEDENTES DESTA CORTE. PLANOS ECONÔMICOS BRESSER, VERÃO, COLLOR I E COLLOR II. LEGITIMIDADE PASSIVA AD CAUSAM. PRESCRIÇÃO. ÍNDICES DE CORREÇÃO.
\end{abstract}

[...] II - No julgamento de Recurso Repetitivo do tipo consolidador de jurisprudência constante de numerosos precedentes estáveis e não de tipo formador de nova jurisprudência, a orientação jurisprudencial já estabilizada assume especial peso na orientação que se firma. III - Seis conclusões, destacadas como julgamentos em Recurso Repetitivo, devem ser proclamadas para definição de controvérsia: $1^{\circ}$ ) A instituição financeira depositária é parte legítima para figurar no pólo passivo da lide em que se pretende o recebimento das diferenças de correção monetária de valores depositados em cadernetas de poupança, decorrentes de expurgos inflacionários dos Planos Bresser, Verão, Collor I e Collor II; com relação ao Plano Collor I, contudo, aludida instituição financeira depositária somente será parte legítima nas ações em que se buscou a correção monetária dos valores depositados em caderneta de poupança não bloqueados ou anteriores ao bloqueio. $2^{a}$ ) É vintenária a prescrição nas ações individuais em que são questionados os critérios de remuneração da caderneta de poupança e são postuladas as respectivas diferenças, sendo inaplicável às ações individuais o prazo decadencial quinquenal atinente à Ação Civil Pública. STJ. REsp. 1107201, Relator Min. Sidnei Beneti, julgado em 08/09/2010 e publicado em 06/05/2011. (BRASIL)

É de se ressaltar que as decisões foram no sentido de atribuir prazo prescricional de 20 anos para o caso das demandas apresentadas porque estavam sob a égide do Código Civil de 1916 que estabelecia em seu art. 177, o prazo genérico de 20 anos para o objeto de tais ações. 


\section{CONSIDERAÇÕES FINAIS}

Diante do conteúdo aqui exposto uma certeza leva o artigo, as contas vinculadas do FGTS, ao longo do período compreendido entre 1999 e 2013, sofreram enorme perda pela aplicação da TR, não se mostrando a melhor metodologia para atualizar o dinheiro do trabalhador.

A notícia desagradável dessa perda pelos trabalhadores soou no mercado a partir de meados de 2012, levando milhares de trabalhadores ingressar em juízo para ver seus direitos protegidos no sentido de reaver mais de $80 \%$ (oitenta por cento) de atualização sobre sua conta de FGTS, conforme indicavam as publicidades.

Os casos encontram-se sub judice e, na atualidade, estão sobrestadas todas as ações cujo objeto é a correção dos saldos das contas vinculadas do FGTS por outro índice que não a TR, aguardando decisão do STJ no recurso REsp 1.381.683-PE, de Relatoria do Min. Benedito Gonçalves que repetirá a decisão para todos os casos análogos.

A justiça deverá se posicionar, decidindo as ações de forma a dar uma decisão justa ao trabalhador no sentido de dar procedência aos pedidos aplicando o índice do IPCA-E, como decidiu no caso dos precatórios ADI 4357/2009, sobre o período não atingido pela prescrição e decadência de 10 anos.

Contudo, diante da atual conjuntura econômica e política do Estado Brasileiro, determinar a aplicação de outro índice que não a TR ensejaria uma dívida a Caixa Econômica Federal, gestora do fundo e consequentemente ao Governo Federal, o que faz com vários trabalhadores fique descrentes com a decisão favorável.

Todavia, serve de pano de fundo, se não ocorrer sua procedência, para alimentar uma mudança na lei 8.036/90, no sentido de atualizar a citada lei para reparar tal prejuízo aos trabalhadores doravante, cambiando a forma de atualização do FGTS para um índice que, de fato, seja para corrigir as perdas do poder aquisitivo da moeda, preservando o direito de propriedade do trabalhador cujo único refúgio financeiro que tem ao ser demitido injustamente é o FGTS. 


\section{REFERÊNCIAS BIBLIOGRÁFICAS}

BRASIL. Consolidação das Leis do Trabalho, Decreto-Lei 5.452, de $1^{\circ}$ de maio de 1943. Disponível em http://www.planalto.gov.br. Acesso em 9 jul. 2015.

BRASIL. Constituição da República Federativa do Brasil de 1988. Disponível em http://www.planalto.gov.br/ccivil_03/constituicao/constituicao.htm. Acesso em 11 jul. 2015.

BRASIL. Código Civil. Disponível em http://www.planalto.gov.br/ccivil_03/leis/2002/L10406.htm. Acesso em 11 jul. 2015.

BRASIL. Lei Complementar n. 110 de 29 de junho de 2001. Institui contribuições sociais, autoriza créditos de complementos de atualização monetária em contas vinculadas do Fundo de Garantia do Tempo de Serviço - FGTS e dá outras providências. Disponível em http://www.planalto.gov.br/CCivil_03/leis/LCP/Lcp110.htm. Acesso em 11 jul. 2015.

BRASIL. Lei n. 5.107, de 13 de setembro de 1966. Cria o Fundo de Garantia do Tempo de Serviço, e dá outras providências. Disponível em https://www.planalto.gov.br/ccivil_03/leis/15107.htm. Acesso em 11 jul. 2015.

BRASIL. Lei n. 8.036, de 11 de maio de 1990. Dispõe sobre o Fundo de Garantia do Tempo de Serviço, e dá outras providências. Disponível em http://www.planalto.gov.br/ccivil_03/leis/L8036consol.htm. Acesso em 9 jul. 2015.

Brasil. Lei n. 12.919, de 24 de dezembro de 2013. Disponível em http://www.planalto.gov.br/ccivil_03/_Ato2011-2014/2013/Lei/L12919.htm. Acesso em 9 jul. 2015.

Brasil. Lei n. 13.080, de 02 de janeiro de 2015. Disponível em http://www.planalto.gov.br/ccivil_03/_Ato2015-2018/2015/Lei/L13080.htm. Acesso em 9 jul. 2015.

BRASIL. Banco Central. Resolução 3.354, de 31/06/2006. Disponível em http://www.bcb.gov.br/pre/normativos/busca/normativo.asp?tipo=res\&ano=2006\&numero=3 354. Acesso em 7 jul. 2015.

BRASIL. Instituto Brasileiro de Geografia e Estatística. Indicadores Conjunturais. Disponível em http://www.ibge.gov.br/home/estatistica/pesquisas/calendario.php. Acessado em 9 jul. 2015

BRASIL. Supremo Tribunal Federal. Ação Direita de Inconstitucionalidade (ADI) 493-DF, Rel. Min. Moreira Alves, trânsito em julgado em 14/09/1992. Disponível em http://www.stf.jus.br/portal/processo/verProcessoAndamento.asp?incidente=1519857. Acesso em 7 jul. 2015.

BRASIL. Supremo Tribunal Federal. Ação Direita de Inconstitucionalidade (ADI) 4.357, Rel. Min. Ayres Britto e Redator para acórdão Min. Luiz Fux, julgada em 25/03/2015 e publicada em 06/08/2015. Disponível em 
http://www.stf.jus.br/portal/processo/verProcessoAndamento.asp?incidente=1519857. Acesso em 10 ago. 2015

BRASIL. Superior Tribunal de Justiça. Recurso Especial 46.372-SP, Rel. Min. Waldemar Zveiter, julgado em 02/05/1995 e publicado em 04/12/1995, Disponível em www.stj.jus.br. Acesso em 7 jul. 2015.

BRASIL. Superior Tribunal de Justiça. Recurso Especial 52.961-RJ, Rel. Min. Pedro Acioli, julgado em 06/09/1994 e publicado em 10/10/1994, Disponível em www.stj.jus.br. Acesso em 7 jul. 2015.

BRASIL. Superior Tribunal de Justiça. Recurso Especial 75.575-SP, Rel. Min. José de Jesus filho, julgado em 25/10/1995 e publicado em 04/12/1995, Disponível em www.stj.jus.br. Acesso em 7 jul. 2015.

BRASIL. Superior Tribunal de Justiça. Recurso Especial 43.055, Rel. Min. Sálvio de Figueiredo Teixeira, julgado em 11/05/1995 e publicado em 18/12/1995. Disponível em www.stj.jus.br. Acesso em 7 jul. 2015

BRASIL. Superior Tribunal de Justiça. Recursos Especiais 7326 e 7327, Min. Rel. Athso Gusmão Carneiro, julgado em 23/04/1991 e publicado em 13/05/1991; julgado em 28/05/1991 e publicado em 1\%07/1991. Disponível em www.stj.jus.br. Acesso em 7 jul. 2015.

BRASIL. Superior Tribunal de Justiça. Recurso Especial 1.133.872, Min. Rel. Massami Uyeda, julgado em 14/12/2011 e publicado em 28/03/2012; Disponível em www.stj.jus.br. Acesso em 7 jul. 2015.

BRASIL. Superior Tribunal de Justiça. Recurso Especial 1.107.201, Min. Rel. Sidnei Beneti, julgado em 08/09/2010 e publicado em 06/05/2011; Disponível em www.stj.jus.br. Acesso em 7 jul. 2015.

BRASIL. Justiça Federal. Subseção Judiciária de Pouso Alegre/MG da Justiça Federal, autos n. 3279-88.2013.4.01.3810, Juiz Márcio José de Aguiar Barbosa, decisão em 16/01/2014.

BRASIL. Justiça Federal. Subseção Judiciária de Curitiba. Autos n. 5009533-

35.2013.404.7002/PR, Juiz Federal Substituto, Diego Viegas Véras, decisão em 15/01/2014.

COSSERMELLI , EDUARDO . Coexistência da estabilidade e regime do FGTS. Revista LTr [S.1.], v.35,n.4,p.279-281,(1971: abr).

DELGADO, Maurício Godinho. Curso de Direito do Trabalho. $13^{\mathrm{a}}$ Ed. São Paulo: LTr, 2014.

GUIMARÃES, Carlos Alfredo Cruz. A prescrição para reclamar os depósitos do FGTS e a natureza jurídica do direito à opção retroativa. A inconstitucionalidade da Emenda Constitucional n 28. Genesis - Revista de Direito do Trabalho. Curitiba, v.16, n.93,p.343353 , set. 2000. 
MARCA, EDMO LIMA. A sistemática do Fundo de Garantia do Tempo de

Serviço. Revista LTr. São Paulo, v.36, n.4, p.282-286, mar. 1972.

OLIVEIRA, Luiz Edgar Ferraz de. Aspectos processuais da Lei complementar $\mathbf{n}^{\circ}$ 110/2001 na Justiça do Trabalho. COAD - Doutrina e Jurisprudência. Rio de Janeiro, v.38, n.3, p.3328, 2004.

PINTO, José Augusto Rodrigues. Curso de Direito Individual do Trabalho: noções fundamentais de direito do trabalho, sujeitos e instituições do direito individual. $3^{\mathrm{a}}$ edição, São Paulo: LTR, 1997.

SCAVONE JUNIOR, Luiz Antonio. Juros no Direito Brasileiro. 4a edição, rev. atual. e ampl. São Paulo: Editora Revista dos Tribunais, 2011. 